\title{
Infrared thermography and behavioral biometrics associated with estrus indicators and ovulation in estrus-synchronized dairy cows housed in tiestalls
}

\author{
H. J. Perez Marquez, ${ }^{1}$ D. J. Ambrose, ${ }^{1,2}$ A. L. Schaefer, ${ }^{1,3}$ N. J. Cook, ${ }^{1,4}$ and C. J. Bench ${ }^{1 *}$ \\ ${ }^{1}$ Department of Agricultural, Food and Nutritional Science, University of Alberta, Edmonton, AB, T6G 2P5, Canada \\ ${ }^{2}$ Livestock Research and Extension Branch, Alberta Agriculture and Forestry, Edmonton, AB, T6H 5T6, Canada \\ ${ }^{3}$ Animal Inframetrics Inc., PO Box 5451, Lacombe, AB, T4L 1X2, Canada \\ ${ }^{4}$ Livestock Research and Extension Branch, Alberta Agriculture and Forestry, Lacombe Research Centre, Lacombe, AB, T4L 1W1, Canada
}

\section{ABSTRACT}

Most Canadian dairy herds operate in tiestall housing $(61 \%)$, where average estrus detection rates may be lower than $54 \%$. The objective of this study was to evaluate infrared thermography and behavioral biometrics as indicators of estrus in dairy cows. Eighteen cyclic multiparous cows (Synch) were subjected to an estrus synchronization protocol, and 18 pregnant cows (control) received a sham protocol on the same schedule and frequency as the cyclic cow treatment. A decline in plasma concentrations of progesterone and the appearance of a dominant follicle using transrectal ultrasonography were used as indirect indicators of estrus, and the disappearance of a dominant follicle was used to confirm ovulation. All cows were monitored via visual cameras to determine the frequency of treading, drinking, neighbor interaction, tail movement, lying, and shifting behaviors. Infrared thermograms were recorded at the eye, muzzle, cheek, neck, front right foot, front left foot, rump, flank, vulva area, tail head, and withers. To evaluate the accuracy of behavioral and thermal parameters, a predefined minimum acceptable value (i.e., threshold) for estrus alerts $(>0.30$ Youden $\mathrm{J}$ index and $>0.60$ area under the curve) was used. Ovulation was confirmed in $14(77.7 \%)$ out of 18 Synch cows. Eye, cheek, neck, rump, flank, vulva area, and wither thermograms exhibited higher temperatures at $48 \mathrm{~h}$ [cycle threshold $(\Delta \mathrm{t})=+0.30$ to $1.20^{\circ} \mathrm{C}$ ] and $24 \mathrm{~h}$ before ovulation compared with $4 \mathrm{~d}$ prior to ovulation $\left(\Delta \mathrm{t}=0.06\right.$ to $\left.0.11^{\circ} \mathrm{C}\right)$ and during ovulation day $(\Delta \mathrm{t}=$ 0.03 to $0.32^{\circ} \mathrm{C}$ ) in the Synch group. In addition, control cows exhibited greater treading activity per day compared with Synch cows (20.84 \pm 0.39 vs. 16.35 events $/ 5$ $\min \pm 0.34$ ), and tail movement frequency was greater

Received June 15, 2018.

Accepted January 22, 2019.

*Corresponding author: bench@ualberta.ca in Synch cows compared with control cows $(14.84 \pm 2.7$ vs. $10.11 \pm 4.7$ events $/ 5$ min). However, within Synch cows, tail movement was the only behavior that significantly increased in frequency $2 \mathrm{~d}$ before ovulation $(11.81 \pm 1.71$ events $/ 5 \mathrm{~min})$ followed by a decrease in frequency $1 \mathrm{~d}$ before ovulation $(4.67 \pm 1.05$ events $/ 5$ min) compared with ovulation day $(0 \mathrm{~d} ; 6.10 \pm 1.25$ events $/ 5 \mathrm{~min}$ ) and during luteolysis (3 d before ovulation; $6.01 \pm 1.25$ events $/ 5 \mathrm{~min})$. Upon evaluation of all variables (thermograms and behavior frequencies) as estrus indicators at 48 and $24 \mathrm{~h}$ before ovulation, treading and tail movements before milking and 9 thermal locations satisfied the predefined minimum acceptable value for estrus alerts. This study demonstrates that fluctuations in radiated temperature measured at specific anatomical locations and the frequency of tail movements and treading behaviors can be used as a noninvasive estrus alerts in multiparous cows housed in a tiestall system.

Key words: estrus indicator, radiated temperature, pipeline housing, movement

\section{INTRODUCTION}

Failure to detect behavioral estrus and false-positive estrus detection can result in missed or mistimed inseminations, which can lead to poor reproductive outcomes and economic losses on dairy farms (Lewis and Newman, 1984; Rae et al., 1999). Typically, ovulation occurs 24 to $30 \mathrm{~h}$ after the onset of standing estrus (Roelofs et al., 2005). Specifically, the onset of standing estrus is associated with peripheral concentrations of progesterone $\left(\mathbf{P}_{4}\right)$ below $0.95 \mathrm{nmol} / \mathrm{L}$ (Holman et al., 2011) and a follicular diameter greater than $15 \mathrm{~mm}$ (Perrya et al., 2017), which is required to achieve ovulation. Visual observation of standing estrus is often cited as the industry standard for estrus detection; however, it has a $54.5 \%$ average estrus detection rate (At Taras and Spahr, 2001). Visual methods rely on 
observations of cows standing to be mounted, which is easily facilitated in freestall housing but is limited to when cows are let out for exercise in tiestall housing systems (Michaelis et al., 2014). Alternatives to visual observation for estrus detection include the use of various electronic aids, many of which have also been found to be more accurate in freestall housing systems (At Taras and Spahr, 2001). The sensitivity of estrus detection for electronic estrus detection aids has been reported within the literature for radio wave transmitters for mounting data (96\%; Xu et al., 1998), activity devices attached to the leg (60\%; Senger, 1994), volatile organic compound electronic nose detectors (86\%; Sanderink et al., 2017), and accelerometers attached to the ear or neck (83-87\%; At-Taras and Spahr, 2001). The use of estrus detection devices combined with visual observation has been found to improve estrus detection by decreasing the difference between the retained value and the true value (error rate) when a single estrus detection method is used (34.6\%) compared with when multiple estrus detection methods are used (12.5\%) in freestall systems (Firk et al., 2003), thus providing support for methods of estrus detection that measure and monitor a variety of parameters.

Overall, estrus detection methods that rely on mounting or other overt ambulatory behaviors work best in environments in which such behaviors are not restricted (e.g., free-access stall systems) compared with systems in which mounting behavior is restricted for most of the day (e.g., tiestall barns). For example, Felton et al. (2012) were unable to detect estrus using pedometers in a tiestall barn despite previous studies finding them to be effective in freestall systems (Roelofs et al., 2005). An additional limitation of visual or mounting-based electronic estrus detection methods is how to detect cows ovulating in the absence of obvious signs of estrus (i.e., silent estrus). Because of these challenges, nonbehavioral methods of detecting either estrus or ovulation, which focus on the use of elevated core body temperature during the estrous period followed by a decrease in core body temperature around the time of ovulation as indicators, have been studied (Lewis and Newman, 1984; Kyle et al., 1998; Suthar et al., 2011). For example, Redden et al. (1993) reported an increase in core body temperature of $0.6 \pm 0.3^{\circ} \mathrm{C}$ during estrus. However, the coefficient of variation for core body temperature measurements equates to $50 \%$, making it an unreliable indicator of estrus if used in isolation from other biomarkers. Furthermore, Hoffmann et al. (2013) concluded that obtaining core body temperatures (e.g., rectal temperatures) is time consuming and disruptive (i.e., invasive) for animals, especially within large herds.

In contrast, infrared thermography (IRT) is a noninvasive technology (Hoffmann et al., 2013) that provides real-time thermal data for the assessment of various physiological conditions in cattle (e.g., infectious diseases). Heat radiated from the body surface is measured by IRT, which is then displayed as a temperature distribution image (Chiang et al., 2008). Each pixel in a radiometric thermal image represents a temperature measurement that can be monitored, recorded, and analyzed (Hurnik et al., 1985). Talukder et al. (2014) demonstrated that IRT can predict ovulation 24 to 48 $\mathrm{h}$ in advance based on variations in skin temperature measured at the vulva of dairy cows housed in a freestall system with an increase of $1.0^{\circ} \mathrm{C}$ at a sensitivity of $83 \%$, specificity of $43 \%$, and a positive predictive value of $71 \%$. In comparison, visual observation of estrus had a lower sensitivity of $67 \%$ but a higher specificity of $86 \%$ (Talukder et al., 2014). We note that sensitivity values, in particular, are important as an indication of how often estrus is detected when it is actually occurring (i.e., true positive detection). Several factors affect the overall accuracy of an estrus detection method, including heat stress (Yániz et al., 2006), farm management practices (Aungier et al., 2012), milk production level (Sangsritavong et al., 2002), and type of housing (freestalls vs. tiestalls; Palmer et al., 2010). As such, reliance on only visual methods of estrus detection, with its lower sensitivity (Talukder et al., 2014), necessitates the search for more reliable and accurate indicators of estrus (or estrus alerts) that are not reliant on overt standing estrus cues. This is particularly important in Canada, where tiestall housing represents $61 \%$ of dairy farms (Denis-Robichaud et al., 2016) and failure to detect estrus has a direct effect on herd reproductive performance and cow longevity, which results in income losses ranging from US $\$ 0.73$ to more than US $\$ 1.24$ per open day per cow following the voluntary waiting period of 50 DIM (de Vries and Conlin, 2003).

More recently, subtle microbehavior biometrics that are thought to prime more overt behavioral indicators of physiological changes associated with ovulation have also been used within a tiestall environment to assess estrus (Guesgen and Bench, 2018). The de novo application of combined behavioral biometrics and IRT in tiestall housing and automated milking systems may serve to further optimize the accuracy of estrus alerts compared with visual observation methods. Therefore, the objectives of this study were to (1) characterize behavioral and thermal biometric patterns of pregnant and cyclic cows around milking time and (2) evaluate the accuracy of IRT and behavioral biometric parameters as noninvasive estrus indicators in cyclic dairy cows in a tiestall housing system. We hypothesized that subtle changes in behavior biometrics associated with lordosis (i.e., standing estrus) and fluctuations in radiated heat emitted from specific anatomical locations can differen- 
tiate the physiological status (pregnant vs. cyclic and cyclic non-estrus vs. cyclic estrus) in dairy cows. Our second hypothesis was that behavior biometrics and fluctuations in radiated heat are able to produce estrus alerts with an estrus detection rate greater than visual estrus detection results (e.g., >54\%) reported in the scientific literature for dairy cows housed in tiestalls.

\section{MATERIALS AND METHODS}

This study was approved by the University of Alberta Animal Care and Use Committee for Livestock (AUP 00001652), and all animals were cared for in accordance with Canadian Council on Animal Care (2009) standards and requirements.

\section{Animals and Housing}

Thirty-six multiparous Holstein cows (18 cyclic, 18 pregnant) were used in this study. The minimum total sample size recommended for IRT data was 6 cows and for behavior data was 7 cows using a hypothesis testing 2-sample inference estimation of sample size and power for comparing 2 means (Rosner, 2006) within an $\alpha$ of 0.05 and a power of 0.80 . Based on the availability of animals and to minimize disturbances during milking, cows were assigned to 3 replicates each of 6 cyclic and 6 pregnant cows. The study was conducted from January to April 2016 (winter to early spring) at the Dairy Research and Technology Centre, a tiestall facility at the University of Alberta (Edmonton, AB, Canada). Cows were milked twice daily (0330-0600 h and 1500-1730 h) in stall using a pipeline milking system.

Cow parity ranged from the second to fifth lactations. Cyclic cows during the study produced $44.10 \pm 15.80$ $\mathrm{kg}$ (mean $\pm \mathrm{SD}$ ) of milk/d and ranged from 45 to 55 DIM. Pregnant cows were $185.77 \pm 19.54$ DIM (mean $\pm \mathrm{SD})$ and $90 \pm 19.91 \mathrm{~d}$ in gestation (mean $\pm \mathrm{SD}$ ), producing $42 \pm 11.30 \mathrm{~kg}$ (mean $\pm \mathrm{SD}$ ) of milk/d. To control for potential exercise-induced thermogenesis, cows were housed in stall for $14 \mathrm{~d}$ continuously with free access to water and fed a TMR once daily (0600 h) formulated for lactating dairy cows per NRC (2001) guidelines. The TMR comprised alfalfa-barley silage, rolled barley-corn, grass hay, and mineral supplements.

\section{Experimental Design}

Using a split-plot over-time experimental design, IRT and behavioral biometric parameters between 2 treatments - cycling (Synch) and pregnant (control) - were compared using an equal number $(\mathrm{n}=18)$ of cows per treatment (total $n=36$ cows). Within the Synch treatment, behavior and radiated temperature variables were further compared during the estrous period with non-estrous periods and ovulation day.

\section{Induction of Estrus}

Synch cows were subjected to a hormonal synchronization protocol to induce estrus. Synch cows were deemed healthy and at least 45 DIM at the start of the synchronization protocol. The timeline for the synchronization protocol used in the cyclic cow treatment is provided in Figure 1. Cows were administered GnRH (100 $\mu$ g i.m.; Fertiline, Vetoquinol N.-A. Inc., Lavaltrie, $\mathrm{QC}$, Canada) and an intravaginal $\mathrm{P}_{4}$ device (CIDR; Zoetis Inc., Kirkland, QC, Canada) on d 1 of the protocol. Prostaglandin $\mathrm{F}_{2 \alpha}(500 \mu \mathrm{g}$ i.m.; Estrumate, Intervet Corp. Inc., Kirkland, QC, Canada) was administrated $12 \mathrm{~h}$ apart during $\mathrm{d} 7$ to induce luteolysis. The CIDR was removed concurrent with the first $\mathrm{PGF}_{2 \alpha}$ injection (Figure 1). Control cows received sham injections (i.m. insertion of needle only) to simulate $\mathrm{GnRH}$ (d 1) and $\mathrm{PGF}_{2 \alpha}$ treatments (d 7), and a CIDR device (same as Synch cows) was inserted on $\mathrm{d} 1$ and removed on $\mathrm{d} 7$ to simulate the synchronization protocol applied to Synch cows (Hittinger et al., 2004; Martinez et al., 2007).

\section{Blood Sampling}

Blood samples were obtained from the coccygeal vein of each cow using 10-mL lithium heparin Vacutainer tubes (Becton Dickinson, Franklin Lakes, NJ) for $\mathrm{P}_{4}$ analysis. Blood samples were collected after morning and afternoon milkings starting on the d 6 of the study and continued for $5 \mathrm{~d}$ in control cows and until ovulation was confirmed or for a maximum of $5 \mathrm{~d}$ after the second $\mathrm{PGF}_{2 \alpha}$ in Synch cows (Figure 1). Plasma was obtained by centrifuging blood samples at 1,940.2 $\times g$ and $4^{\circ} \mathrm{C}$ for $20 \mathrm{~min}$ and stored in 1.5-mL microcentrifuge tubes (Fisher Scientific, Waltham, MA) at $-20^{\circ} \mathrm{C}$ until hormone assays were performed.

\section{Progesterone Assay}

Progesterone assays were performed at the endocrine laboratory of Prairie Diagnostic Services Inc. at the University of Saskatchewan (Saskatoon, SK, Canada) using a solid-phase RIA (ImmuChem; MP Biomedicals LLC, Orangeburg, NY). Plasma samples were analyzed in a single assay with a duplicate analysis of every third sample. Over a concentration range of 3.20 to 33.20 $\mathrm{nmol} / \mathrm{L}$, the interassay coefficient of variation was 10.90 to $21.70 \%($ mean $=13.80 \%)$ and the intra-assay coefficient of variation was 12.20 to $27.40 \%$ (mean = $18.10 \%)$. 
IRT and Digital video recordings $3 \times /$ day during a.m., p.m. milking and mid-day

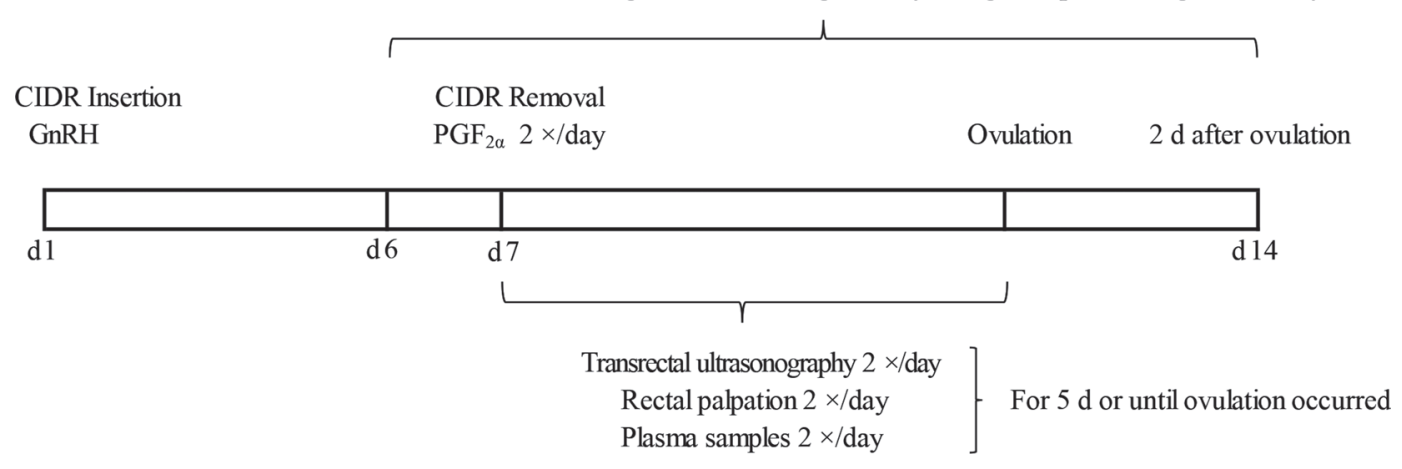

Figure 1. Timeline of experimental events. Gonadotropin-releasing hormone was given (d 1 of protocol) to synchronize follicular development in the synchronized (Synch) group and a sham injection (insertion of a needle only) was given to the control group, and an intravaginal progesterone device (CIDR) was inserted concurrently in both groups. Two injections of $\mathrm{PGF}_{2 \alpha}$ were given $12 \mathrm{~h}$ apart to induce luteolysis on d 7 in the Synch cows, and sham injections on the same frequency as the Synch group were given to the control group. Transrectal ovarian ultrasonography was used to measure dominant follicles and confirm ovulation in Synch cows, whereas control cows were subjected to palpation per rectum. Plasma samples were obtained $12 \mathrm{~h}$ apart (0600 and $1800 \mathrm{~h}$ ) to determine progesterone concentrations from Synch and control cows. Infrared thermograms (IRT) and digital video recordings were performed to measure changes in behavior frequencies and skin radiated temperatures on days approaching ovulation from d 6 until $2 \mathrm{~d}$ after ovulation.

\section{Ultrasound Scanning}

Prior to the start of the study, each cow's reproductive tract was scanned using transrectal ultrasonography (ultrasound Aloka SSD-500 3.5-MHz linear transducer; Aloka Co. Ltd., Tokyo, Japan) to reconfirm pregnancy in control cows that had been previously diagnosed pregnant and to confirm ovarian cyclicity in cows assigned to the Synch treatment. Cyclic cows bearing a corpus luteum at the first examination confirmed ovarian cyclicity and were selected to be placed in the Synch group. Control cows were selected between 60 and 120 $\mathrm{d}$ of gestation (based on breeding records) to reduce the likelihood of pregnancy loss during the study period. Ultrasound scans were conducted twice per day following morning and afternoon milking starting on $\mathrm{d} 7$ to monitor follicular growth and corpus luteum regression and to confirm ovulation in Synch cows. Control cows were each subjected to sham rectal palpation at the same frequency and duration of ultrasound scanning as Synch cows to simulate the same level of invasiveness in both groups of cows. Ovulation was declared when a dominant follicle previously documented had disappeared in successive scanning sessions, followed by the appearance of a corpus luteum in the same location as the dominant follicle. Specifically, ovulation time was declared as when the ultrasound scan found the dominant follicle had disappeared.

\section{Onset of Estrus}

In this study, the estrous period was defined as the period of time before ovulation that coincided with a decrease in peripheral concentrations of $\mathrm{P}_{4}$ below 0.95 nmol/L (Holman et al., 2011) and a follicular diameter larger than $15 \mathrm{~mm}$ (Perrya et al., 2017). For statistical analysis and assessment of estrus alerts, both 24 and $48 \mathrm{~h}$ before ovulation were evaluated because $\mathrm{P}_{4}$ levels were expected to be below $0.95 \mathrm{nmol} / \mathrm{L}$ and follicular sizes to be greater than $15 \mathrm{~mm} 48$ and $24 \mathrm{~h}$ before ovulation. No mounting or standing to be mounting were observed in this study because all behavior observations took place within each cow's tiestall environment.

\section{Infrared Thermography}

Infrared radiometric thermal images were individually captured at 11 anatomical locations at 5-s intervals between each location per cow at morning and afternoon milking and at midday (a nonmilking time). Infrared radiometric images of $320 \times 240$ pixels with a thermal sensitivity of $<0.04^{\circ} \mathrm{C}$ at $30^{\circ} \mathrm{C}$ and accuracy of $\pm 2 \%$ of reading were recorded using a FLIR T450SC thermal camera (FLIR Systems Ltd., Burlington, ON, Canada) at the 11 anatomical locations, some of which have been previously investigated by other studies: muzzle, vulva (Talukder et al., 2014), front right foot, front left foot, rump, flank (Montanholi et al., 2008), tail head (InterAg, Hamilton, New Zealand), eye, cheek (Schaefer et al., 2012), withers, and neck (Figure 2). Thermal images were collected for 9 consecutive days, starting on d 6 of the study until d 14, to establish a starting point for the estrous period during luteal regression and to analyze any thermal fluctuations before and during ovulation day. To maintain a consistent camera distance, thermal images were collected at a 

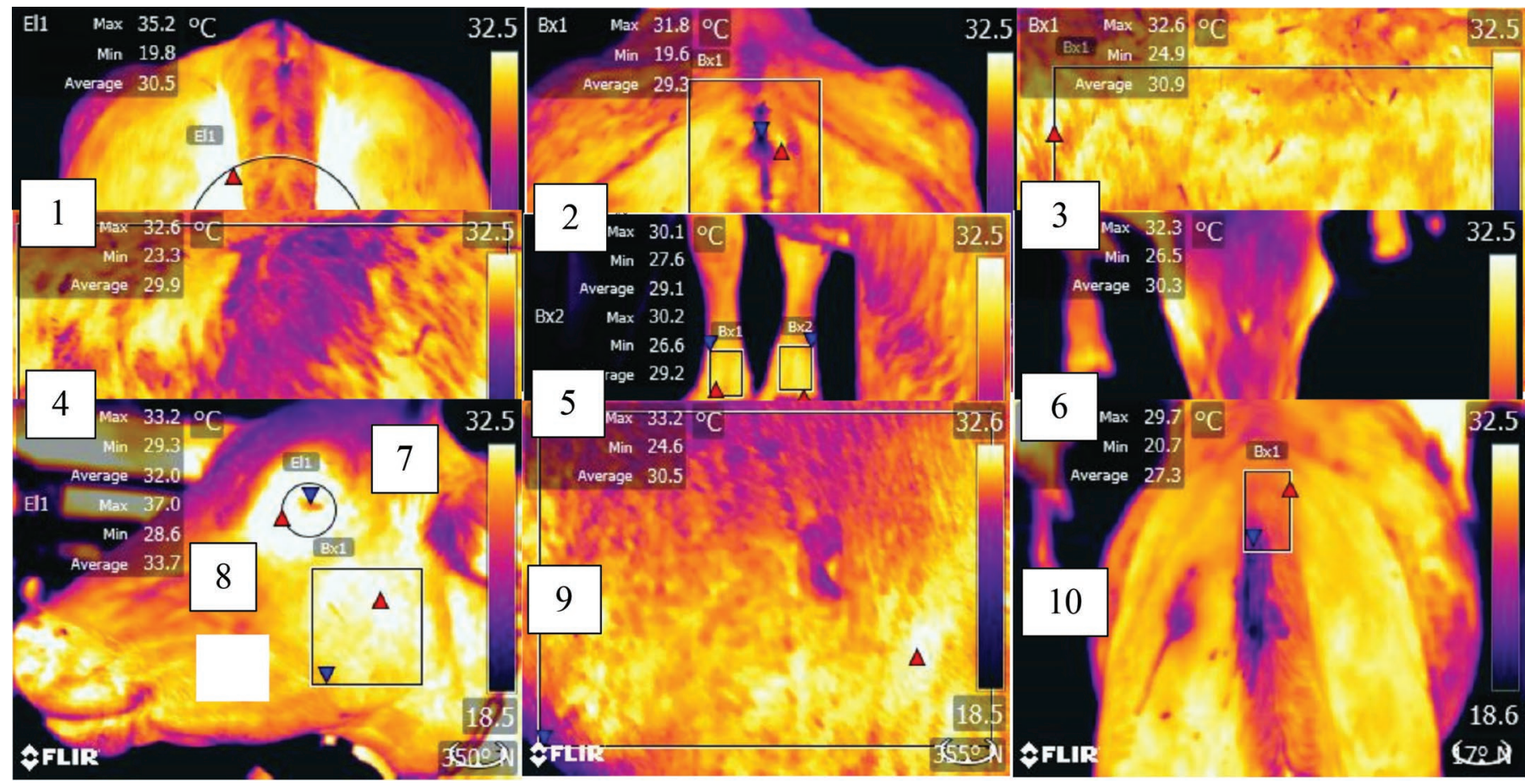

Figure 2. Sample thermal images from 10 anatomical locations, including the vulva area (1), tail head (2), rump (3), flank (4), front right foot and front left foot (5), muzzle (6), eye (7), cheek (8), neck (9), and withers (10). The squares and circles in the thermal pictures represent the area used to identify the maximum (Max) radiated temperature for each anatomical location. Min $=$ minimum.

1-m perpendicular angle from the point of interest on each cow using a GLM15 50-foot laser tool measurement (Robert Bosch Tool Co., Mount Prospect, IL). Ambient temperature $\left({ }^{\circ} \mathrm{C}\right)$ and percent relative humidity (\%) were recorded using a weather meter (Kestrel 3000, Kestrel Nielsen-Kellerman Co., Boothwyn, PA) before each infrared recording. The ratio of energy radiated from a material (e.g., the cow's skin surface), or emissivity, was set to 0.98 to calibrate each infrared camera in accordance with manufacturer recommendations for the scanning of live tissues.

Thermal images were processed using FLIR Tools software (FLIR Systems Ltd.) to determine maximum, minimum, and average radiated temperatures. Specifically, FLIR Tools ensured that the same number of pixels were recorded at each anatomical location for consistency across thermal images.

\section{Behavior Observations}

To determine the frequency of behavior events relative to ovulation, cows were monitored using digital video recordings (Swann 8-ch 960H DVR, Swann Communications Inc., Santa Fe Springs, CA) and coded for treading, drinking, tail movement, lying, shifting, and neighbor interaction as described in Table 1. Sur- veillance cameras were mounted at a distance of $2 \mathrm{~m}$ behind each cow, at an angle of $45^{\circ}$, to record each cow and her immediate surroundings. Behavior data were recorded for 5 min continuously before, during, and after each milking and at midday for $9 \mathrm{~d}$ from $\mathrm{d} 6$ to 14 to coincide with IRT scans.

Each of 8 observers were randomly assigned a set of videos except for 3 videos, which were common to all observers to evaluate interobserver variation relative to prescored video standards. Interobserver variation was evaluated using a Kappa coefficient calculated using Microsoft Excel 2013 (Microsoft Corp., Redmond, WA), and an interobserver reliability of $85 \%$ was achieved.

\section{Statistical Analysis}

Data were analyzed using SAS (version 9.4, SAS Institute Inc., Cary, NC) to identify significant behavioral and physiological parameters by day relative to ovulation. Each cow served as the experimental unit. Sample days were standardized $(\mathrm{d}-5,-4,-3,-2,-1,0,1$, and 2) using ovulation as d 0 in Synch cows. Only Synch cows in which ovulation was confirmed were included in data analysis $(\mathrm{n}=14 ; 4$ cycling cows did not ovulate) and compared with control cows $(\mathrm{n}=18)$. The Univariate procedure was used to evaluate data normality 
Table 1. Ethogram of cow behaviors observed during morning and afternoon milkings and at midday ${ }^{1}$

\begin{tabular}{ll}
\hline Behavior & Description \\
\hline Treading & Cow lifts either left or right back foot and returns foot to the floor. Can be a full step or semi-step (only 1 foot \\
& moves but the other remains in its position). \\
Drinking & Cow approaches the water bowl and proceeds to place snout in water bowl. \\
Neighbor interactions & Any kind (e.g., pushing, licking, scratching) of contact between one cow and the cow on either its left or right \\
& side. \\
Tail movement & Each tail movement from side to side. \\
Shifting & Cow changes position without any foot movement (step). \\
Lying & Cow is sternally or laterally recumbent.
\end{tabular}

${ }^{1}$ Continuous behavior sampling was conducted 5 min before, during, and after milking.

and to identify data outliers. A normal distribution was assessed using a Kolmogorov-Smirnov test $(P>0.05)$ in which all thermal data complied with normality assumptions; however, behavioral data did not satisfy all normality assumptions. Models were fitted to a generalized linear mixed model using the Glimmix procedure. For all analyses, the type 3 test was requested with the inverse (ilink) function specified. All results are presented as least squares means and standard error of the means calculated using a Bonferroni means separation test. Differences were considered significant if $P<0.05$, a tendency if $0.05 \leq P<0.10$, and not significant if $P$ $\geq 0.10$. Peripheral concentrations of $\mathrm{P}_{4}$ and follicular size were analyzed using sample day as a fixed variable.

\section{Behavior Analysis}

Behavior data were analyzed using the Glimmix procedure with a Poisson distribution and the log link function specified. Fixed variables in the model included treatment (control and Synch), sample day relative to ovulation ( $\mathrm{d}-5,-4,-3,-2,-1,0,1$, and 2 ), and sample time (morning milking, midday milking, afternoon milking), and observer (A, AN, E, EM, $\mathrm{H}, \mathrm{K}$, and $\mathrm{N})$, replicate $(1,2$, and 3 ), and cow were included as random effects. Observer and replicate were removed from subsequent analysis because they were found not to be statistically significant. Following preliminary analysis, treading and tail movement behaviors were further analyzed to determine any effect of morning versus afternoon milking as well as milking order (before, during, and after milking) because only treading and tail movement were found to be statistically significant.

\section{Radiated Temperature Analysis}

The maximum radiated temperature was used based on the hottest pixel in each thermogram to eliminate the potential of foreign debris to confound thermal data. Radiated heat from all anatomical locations was compared at different times of the day (e.g., morning, afternoon, and midday) to identify any effect of time of day relative to ovulation as well as to determine which scanning time produced the most efficient estrus alert. Additionally, pooled radiated temperature data from morning milking, afternoon milking, and midday thermograms (total of 3 IRT images per anatomical location) was used to run a daily radiated temperature average (Davg) analysis for each anatomical location to compensate for any effect of sample time.

To compensate for the effect of ambient temperature on radiated temperature, residual radiated temperature was calculated by comparing the observed radiated heat from each anatomical location with a predicted radiated temperature (Cook et al., 2016). To predict radiated temperature from each anatomical location, a simple linear regression $(\mathrm{Y}=\mathrm{a}+\mathrm{bX})$ was run per cow. To do this, ambient temperature was assigned as the independent variable (x-axis) and the observed radiated temperature was assigned as the dependent variable (y-axis). Potential confounding environmental effects were thereby eliminated to obtain radiated temperature changes relative to the estrous period according to the following equation (Cook et al., 2016):

radiated heat residual $=$ radiated heat observed - radiated heat predicted.

All thermogram data for the vulva area, tail head, rump, flank, front right foot, front left foot, muzzle, eye, cheek, neck, and withers were analyzed using the Glimmix procedure with a normal distribution specified. Experimental unit was identified as a random effect. Fixed effects in the model included treatment, replicate, relative humidity and ambient temperature, sample day, and sample time.

\section{ROC Curve Analysis}

Receiver operating characteristic (ROC) curves were constructed using MedCalc Statistical Software (version 16.4.3; MedCalc Software bvba, Ostend, Bel- 
gium) to evaluate the proportion of true-positive estrus (sensitivity) and the incidence of true-negative estrus (specificity) as a measure of estrus detection accuracy. As previously indicated, the estrous period was determined based on the concentration of $\mathrm{P}_{4}(<0.95 \mathrm{nmol} / \mathrm{L}$; Holman et al., 2011) and follicular size $(>15 \mathrm{~mm})$ as reported by Perrya et al. (2017). For ROC curve analysis, data from Synch cows were binomially categorized based on estrous period (1) versus non-estrus (0) for each sample day (d -4 to 0 ). Estrus indicators were evaluated using the optimum reference value as an estrus alert for each variable, first at $48 \mathrm{~h}$ before ovulation and again at $24 \mathrm{~h}$ before ovulation for all sample days and to compare the optimum estrus alerts by estrus days (48 vs. $24 \mathrm{~h}$ ). Maximum and residual radiated temperature data were evaluated for all anatomical locations at morning, afternoon, and midday and using Davg for both 24- and 48-h estrous periods. Similar to radiated temperature, all behaviors were tested before, during, and after milking for both estrus alert periods evaluated. Referent test values were determined when sensitivity and specificity were at similar values because sensitivity and specificity are inversely related, which means specificity would decrease at a higher sensitivity (Obuchowski, 2005). This provided a standardized way of choosing a referent among different tests. We calculated measures of test performance at the level of the referent, with the highest Youden J index serving as the optimum referent. The Youden index gives equal weight to false-positive and false-negative estrus values with a range of -1 to 1 for each variable (behavioral and radiated temperature). The area under the curve (AUC) was calculated as an accessory classification analysis as an indicator of the most accurate estrus alert variables. The minimum acceptable value (i.e., threshold) for estrus alerts was predetermined as $0.30 \mathrm{~J}$ index and 0.60 AUC for all IRT and behavioral variables based on the percentage estrus detection rate for $0.30 \mathrm{~J}$ index (a specificity of estrus detection rate of $55 \%$ ), which is comparable with visual observation estrus detection rates previously cited in the scientific literature. Follicular size and $\mathrm{P}_{4}$ concentrations were evaluated using ROC curves and used as the basis of comparison (i.e., as the most efficient methods to detect estrus) for the evaluation of behavioral biometrics and radiated temperature variables.

\section{RESULTS}

Control (pregnant) cows had higher concentrations of $\mathrm{P}_{4}$ compared with Synch cows $(P \leq 0.01)$. However, $\mathrm{P}_{4}$ concentrations within control cows did not differ significantly by sample day (d $1: 25.84 \mathrm{nmol} / \mathrm{L} \pm 2.20$; d 2: $27.42 \mathrm{nmol} / \mathrm{L} \pm 1.55 ;$ d $3: 23.22 \mathrm{nmol} / \mathrm{L} \pm 1.58$; d 4: $25.28 \mathrm{nmol} / \mathrm{L} \pm 1.61 ; \mathrm{d}$ 5: $22.05 \mathrm{nmol} / \mathrm{L} \pm 1.61)$ during the study $(P>0.15)$. Progesterone concentration decreased $(-8.83 \mathrm{pmol} / \mathrm{L} \pm 2.64)$ on $\mathrm{d}-3$ before ovulation, and regression of the corpus luteum was confirmed in all 18 Synch cows. The highest $\mathrm{P}_{4}$ concentration was observed at $120 \mathrm{~h}$ before ovulation $(\mathrm{d}-5$; $11.20 \mathrm{nmol} / \mathrm{L} \pm 2.70)$ and then decreased at $48 \mathrm{~h} \mathrm{(d}$ $-2 ; 0.77 \mathrm{nmol} / \mathrm{L} \pm 0.44)$ and $24 \mathrm{~h}(\mathrm{~d}-1 ; 0.09 \mathrm{nmol} / \mathrm{L}$ $\pm 0.15)$, with the lowest concentration $(0.02 \mathrm{nmol} / \mathrm{L} \pm$ 0.12 ) on day of ovulation (d 0). Nonovulating Synch cows during the study period had higher $\mathrm{P}_{4}$ concentrations $(1.25 \mathrm{nmol} / \mathrm{L} \pm 1.07)$ during the expected time of estrus (48 and $24 \mathrm{~h}$ ).

\section{Ovarian Ultrasonography}

Ovarian ultrasonography confirmed ovulation in 14 $(77.7 \%)$ out of the 18 cows synchronized during the study period. One cow (7.1\%) ovulated within $1 \mathrm{~d}$ of CIDR removal, 3 (21.4\%) within $2 \mathrm{~d}, 3(21.4 \%)$ within $3 \mathrm{~d}, 4(28.5 \%)$ within $4 \mathrm{~d}$, and $3(21.4 \%)$ within $5 \mathrm{~d}$. Follicular size was largest at $2 \mathrm{~d}(17.84 \mathrm{~mm} \pm 1.39)$ and $1 \mathrm{~d}(19.16 \mathrm{~mm} \pm 1.38)$ before ovulation compared with days preceding CIDR removal $(\mathrm{d}-5: 15 \mathrm{~mm} \pm 2.65$; $\mathrm{d}-4: 16.91 \mathrm{~mm} \pm 1.53 ; \mathrm{d}-3: 17 \mathrm{~mm} \pm 1.55)$. Synch cows that did not ovulate had a larger follicular size $(25.50 \mathrm{~mm} \pm 2.62)$ than the rest of the Synch group $(19.16 \mathrm{~mm} \pm 1.38)$ at 48 and $24 \mathrm{~h}$ prior to ovulation.

\section{Behavior Frequencies}

The frequency of treading $(P=0.01)$ and tail movement $(P=0.01)$ differed between Synch and control cows. Control cows exhibited greater treading activity per day $(P=0.01)$ compared with Synch cows $(20.84 \pm$ 0.39 vs. $16.35 \pm 0.34$ events $/ 5$ min). However, treading activity did not change significantly in Synch cows in the days leading up to ovulation $(P=0.59)$.

Tail movement frequency was greater in Synch cows $(P<0.01)$ compared with control cows during the $2 \mathrm{~d}$ preceding ovulation $(14.84 \pm 2.7$ vs. $10.11 \pm 4.7$ events/5 min). Furthermore, Synch cows exhibited consistent tail movement frequencies during the premilking time on $\mathrm{d}-5$ and $-3(7.50 \pm 4.99$ and $7 \pm 1.97$ events $/ 5$ min). However, an increase in tail movement frequency was observed on $\mathrm{d}-4(13.42 \pm 3.57$ events $/ 5 \mathrm{~min})$ and again $48 \mathrm{~h}$ before ovulation $(\mathrm{d}-2$ : $11.81 \pm 1.71$ events $/ 5 \mathrm{~min}$ ), followed by a decrease in tail movements approximately $24 \mathrm{~h}$ before ovulation $(\mathrm{d}-1: 4.67 \pm 1.05$ events $/ 5 \mathrm{~min}$ ) and during ovulation (d 0: $6.18 \pm 1.20$ events $/ 5 \mathrm{~min}$ ). Control and Synch cows exhibited no significant differences for days relative to ovulation for drinking $(P=0.45)$, neighbor interaction $(P=0.47)$, lying $(P=0.96)$, or shifting behaviors $(P=0.40)$. 


\section{Radiated Temperature}

Raw radiated temperature differed between control and Synch cows $(P<0.05)$ for 6 IRT locations (Table $2)$. Other variables found to influence radiated temperature in both groups included ambient temperature and sample time per day $(P<0.05)$. However, no interactions between fixed variables were found. Synch cows exhibited an increase in radiated temperature during the afternoon milking period in the days approaching ovulation ( $\mathrm{d}-2$ and $-1 ; P<0.05)$, whereas control cows did not $(P>0.10)$. Specifically, 9 anatomical locations (vulva area, tail head, muzzle, front left foot, front right foot, rump, cheek, neck, and withers) exhibited an increase in radiated temperature during the last $48 \mathrm{~h}\left(+0.30\right.$ to $\left.1.20^{\circ} \mathrm{C} ; P<0.05\right)$ before ovulation (d -2 and $-1 ; P<0.05$ ), whereas the remaining locations (i.e., eye and flank) did not show any significant changes in radiated temperature $\left(+0.10\right.$ to $0.20^{\circ} \mathrm{C} ; P$ $>0.10)$ within Synch cows. No statistical differences in thermal data obtained during the morning milking, midday milking, or Davg were found within the Synch treatment group for the days approaching ovulation.

\section{ROC Curve Analysis}

Referent values for each estrus alert (24 and $48 \mathrm{~h}$ ) as well as the corresponding $\mathrm{J}$ index, sensitivity, specificity, and AUC for $\mathrm{P}_{4}$, follicular size, IRT, and behavioral parameters are presented in Table 3 and Figure 3 . The highest J index and AUC values were reached when follicular sizes were greater than $18.25 \mathrm{~mm}(0.55 \mathrm{~J}$ index; 0.79 AUC) $48 \mathrm{~h}$ before confirmed ovulation. Drinking, shifting, neighbor interaction, and lying behavior events did not meet the predetermined performance threshold $(<0.30 \mathrm{~J}$ index and $<0.60 \mathrm{AUC})$ and were dropped from further analysis. Tests for performance of raw radiated temperatures were found to be diagnostically relevant for estrus detection, although the test performances varied among anatomical locations. Thermal data obtained from the tail head, front left foot, front right foot, eye, and muzzle did not satisfy preset minimum performance values $(<0.30 \mathrm{~J}$ index; $<0.60$ AUC), nor did any IRT parameters obtained during the morning milking period. Overall, residual IRT data yielded higher performance results for most IRT locations at all sample times and for both estrus alert periods evaluated. Residual IRT data obtained at midday and during the afternoon milking period were characterized by an increase in radiated temperature compared with residual IRT during the morning milking, which exhibited a decrease relative to the referent test value, which satisfied the performance test to create an estrus alert for both periods (24 and $48 \mathrm{~h}$ ). Nei-
Table 2. Treatment comparison of the average radiated temperature between the 2 treatments ${ }^{1}$ from all anatomical locations

\begin{tabular}{lcccccc}
\hline & \multicolumn{2}{c}{ Control } & & \multicolumn{2}{c}{ Synch } & \\
\cline { 2 - 3 } Location & LSM & \multirow{2}{*}{ SEM } & & LSM & SEM & \\
& & & & & \\
Vulva area & 34.86 & 0.05 & & 35.32 & 0.05 & 0.01 \\
Tail head & 32.19 & 0.07 & & 31.99 & 0.07 & 0.06 \\
Rump & 32.87 & 0.06 & & 33.01 & 0.06 & 0.13 \\
Flank & 33.21 & 0.07 & & 33.04 & 0.07 & 0.07 \\
Left foot & 30.73 & 0.11 & & 30.88 & 0.11 & 0.35 \\
Right foot & 30.85 & 0.12 & & 31.00 & 0.11 & 0.36 \\
Muzzle & 32.51 & 0.09 & & 33.46 & 0.09 & 0.01 \\
Cheek & 32.31 & 0.08 & & 31.22 & 0.08 & 0.01 \\
Eye & 35.69 & 0.04 & & 35.99 & 0.04 & 0.01 \\
Neck & 33.61 & 0.07 & & 33.32 & 0.07 & 0.02 \\
Withers & 31.84 & 0.09 & & 32.34 & 0.09 & 0.01 \\
\hline
\end{tabular}

${ }^{1}$ Eighteen cyclic multiparous cows (Synch) were subjected to an estrus synchronization protocol, and 18 pregnant cows (control) received a sham protocol on the same schedule and frequency as the cyclic cow treatment.

ther muzzle nor tail head residual radiated temperature satisfied the minimum performance standards for either estrus period at any sample time (Table 3).

\section{DISCUSSION}

The first objective of this research was to characterize behavioral and thermal biometric patterns of pregnant and cyclic cows around milking time because the application of IRT and behavior biometrics may be helpful for identifying non-estrus cows in addition to cows in estrus for use as an estrus alert. Our results found that IRT and behavior biometrics do indeed differ between pregnant versus cyclic and estrus versus non-estrus dairy cows.

The difference in radiated temperature between control and Synch groups is attributed to the increase in radiated temperature in cyclic cows during the estrous period. Synch cows exhibited higher mean IRT temperatures for the vulva area, muzzle, eye, and withers compared with control cows during the study period. Thermal biometrics revealed an increase in radiated temperature of +0.50 and $1.20^{\circ} \mathrm{C} 48 \mathrm{~h}$ before ovulation at several body landmarks, opposite to the significant decrease in $\mathrm{P}_{4}$ during the same time frame before ovulation (i.e., during the estrous period), which agrees with the findings of Talukder et al. (2014). One possible explanation is that the increase in radiated temperature could be associated with increased activity before ovulation (Walton and King, 1986). However, during this study, control and Synch cows remained in a tiestall environment in which overt movements were limited. Additionally, Frascarolo et al. (1990) demonstrated that the presence of $\mathrm{P}_{4}$ inhibits warm-sensitive neurons and activates cold-sensitive neurons in the anterior 
hypothalamic area in rats. This same $\mathrm{P}_{4}$ mechanism could explain why pregnant cows did not show higher radiated temperatures compared with Synch cows during estrus in the current study. It has also been previously postulated that estradiol, the LH surge, and the GnRH hypothalamic response in cyclic cows may increase radiated temperature (Talukder et al., 2014); however, these parameters were not measured in the current study.

Some of the challenges with IRT measurements are increases in temperature as a result of physical activity, feed intake, and variations in the ambient environment. Variations in focus, distance, camera angle (Talukder et al., 2014), cleanliness of the skin surface, and any subjectivity in the manual processing of thermal images can also affect radiated temperature data. However, every attempt was made in the present study to minimize these factors. To identify radiated temperature changes throughout the estrous cycle, sample time and ambient temperature effects were accounted for by calculating residual radiated temperature for each IRT measurement (Cook et al., 2016). Overall, residual temperature was found to be of greater diagnostic relevance compared with raw temperature data. Specifically, changes in radiated temperature 48 and $24 \mathrm{~h}$ before ovulation were compared with a luteal regression time frame $(\mathrm{d}$

Table 3. Test of performance results for progesterone, follicular size, behavioral, and infrared thermography (IRT) parameters from Synch cows ${ }^{1}$ using receiver operating characteristic curve analysis ${ }^{2}$

\begin{tabular}{|c|c|c|c|c|c|c|}
\hline Parameter & S time ${ }^{3}$ & $\mathrm{~J}$ index ${ }^{4}$ & R-value ${ }^{5}$ & Sensitivity & Specificity & $\mathrm{AUC}^{6}$ \\
\hline \multicolumn{7}{|l|}{ Estrus alert at $24 \mathrm{~h}$} \\
\hline Progesterone & a.m. and p.m. & 0.35 & $\leq 0.15$ & 90.91 & 44.34 & 0.66 \\
\hline Follicular size & a.m. and p.m. & 0.39 & $\geq 16.50$ & 63.64 & 54.74 & 0.65 \\
\hline Treading & A & 0.38 & $<16.00$ & 76.92 & 60.98 & 0.65 \\
\hline Tail movement & $\mathrm{B}$ & 0.34 & $\leq 4.00$ & 69.23 & 64.44 & 0.68 \\
\hline Tail movement & $\mathrm{A}$ & 0.38 & $\overline{<} 6.00$ & 76.92 & 60.98 & 0.67 \\
\hline Vulva area raw IRT & Midday & 0.33 & $>35.90$ & 53.85 & 79.17 & 0.65 \\
\hline Rump raw IRT & Midday & 0.31 & $>32.20$ & 100.00 & 31.25 & 0.63 \\
\hline Cheek raw IRT & p.m. & 0.34 & $>32.80$ & 53.85 & 80.00 & 0.65 \\
\hline Neck raw IRT & p.m. & 0.47 & $>33.60$ & 84.62 & 62.75 & 0.76 \\
\hline Neck raw IRT & Davg & 0.38 & $>33.50$ & 69.23 & 68.63 & 0.64 \\
\hline Flank res IRT & p.m. & 0.40 & $\leq 0.19$ & 100.00 & 40.43 & 0.60 \\
\hline Cheek res IRT & p.m. & 0.45 & $>0.01$ & 84.62 & 60.00 & 0.75 \\
\hline Neck res IRT & p.m. & 0.43 & $>-0.03$ & 92.31 & 50.98 & 0.70 \\
\hline Withers res IRT & a.m. & 0.30 & $\leq-0.53$ & 46.15 & 84.31 & 0.64 \\
\hline Withers res IRT & Midday & 0.30 & $>0.30$ & 53.85 & 76.60 & 0.62 \\
\hline \multicolumn{7}{|l|}{ Estrus alert at $48 \mathrm{~h}$} \\
\hline Progesterone & a.m. and p.m. & 0.38 & $<0.06$ & 84.62 & 53.85 & 0.66 \\
\hline Follicular size & a.m. and p.m. & 0.55 & $>18.25$ & 76.92 & 78.49 & 0.79 \\
\hline Vulva area raw IRT & p.m. & 0.36 & $>36.40$ & 46.15 & 90.20 & 0.70 \\
\hline Rump raw IRT & p.m. & 0.42 & $>33.60$ & 76.92 & 64.71 & 0.62 \\
\hline Flank raw IRT & Midday & 0.35 & $>32.90$ & 84.62 & 50.00 & 0.69 \\
\hline Withers raw IRT & Midday & 0.40 & $>33.40$ & 61.54 & 78.72 & 0.64 \\
\hline Vulva area res IRT & p.m. & 0.35 & $>0.49$ & 38.46 & 96.08 & 0.66 \\
\hline Rump res IRT & Davg & 0.42 & $<-0.33$ & 53.85 & 88.24 & 0.63 \\
\hline Flank res IRT & Davg & 0.46 & $\overline{\leq}-0.59$ & 53.85 & 92.16 & 0.74 \\
\hline Front right foot res & Davg & 0.39 & $\leq 0.08$ & 92.31 & 47.06 & 0.67 \\
\hline Front left foot res & Midday & 0.33 & $>0.25$ & 76.92 & 56.25 & 0.63 \\
\hline Front left foot res & Davg & 0.34 & $\leq-0.22$ & 61.54 & 72.55 & 0.62 \\
\hline Eye res IRT & a.m. & 0.32 & $\overline{>}-0.04$ & 84.62 & 47.06 & 0.68 \\
\hline Eye res IRT & Davg & 0.30 & $\leq-0.13$ & 53.85 & 76.47 & 0.65 \\
\hline
\end{tabular}

${ }^{1}$ Eighteen cyclic multiparous cows (Synch) were subjected to an estrus synchronization protocol, and 18 pregnant cows (control) received a sham protocol on the same schedule and frequency as the cyclic cow treatment. ${ }^{2}$ Significant results are presented $(>0.3 \mathrm{~J}$ index and 0.6 AUC) for all parameters (progesterone, follicular size, IRT, and behavioral biometrics) at different sample times and estrous periods ( 24 and $48 \mathrm{~h}$ prior to ovulation). The $\mathrm{J}$ index represents the relative contribution of true estrus and non-estrus test results by expressing proportions within their respective groups (estrus and non-estrus). The optimum balance reference point was identified as the highest $\mathrm{J}$ index value and AUC and reflects the efficiency of each variable by expressing the true estrus (sensitivity) and true negatives (specificity). res $=$ residual.

${ }^{3} \mathrm{~S}$ time $=$ data collection of behavioral and IRT data per day. $\mathrm{A}=$ behavior data collected 5 min before morning (a.m.) milking; $\mathrm{B}=$ behavior data collected 5 min before afternoon (p.m.) milking; Davg = radiated temperature average per day.

${ }^{4} \mathrm{~J}$ index $=$ Youden index output from receiver operating characteristic curve analysis.

${ }^{5} \mathrm{R}$-value $=$ optimum reference value identified at highest $\mathrm{J}$ index

${ }^{6} \mathrm{AUC}=$ area under the curve. 
A

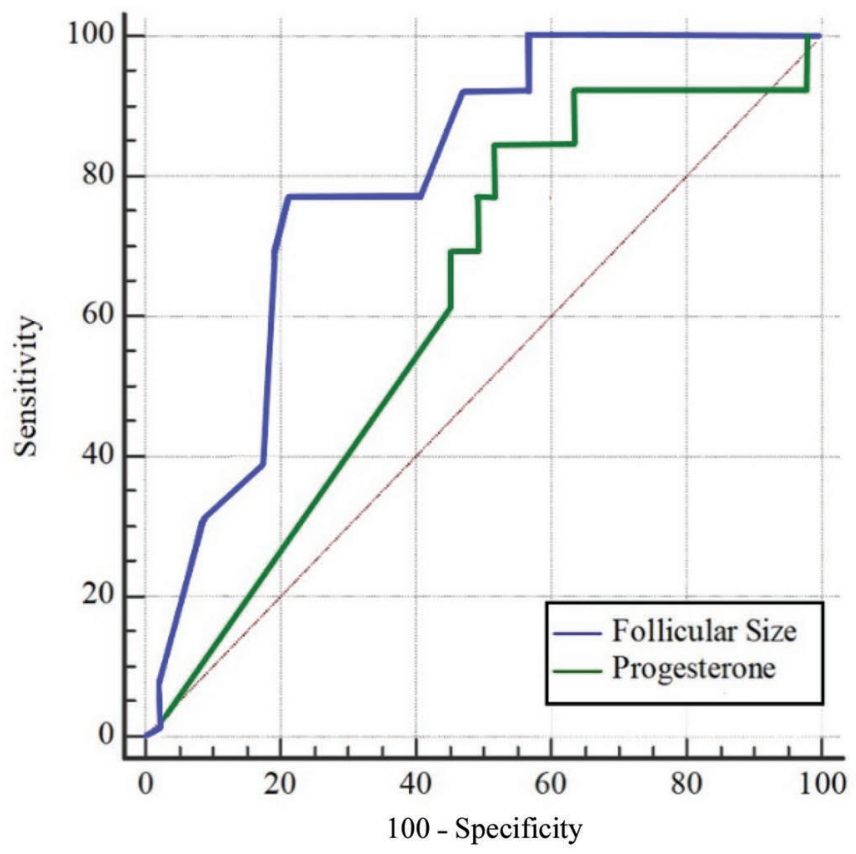

$\mathrm{C}$

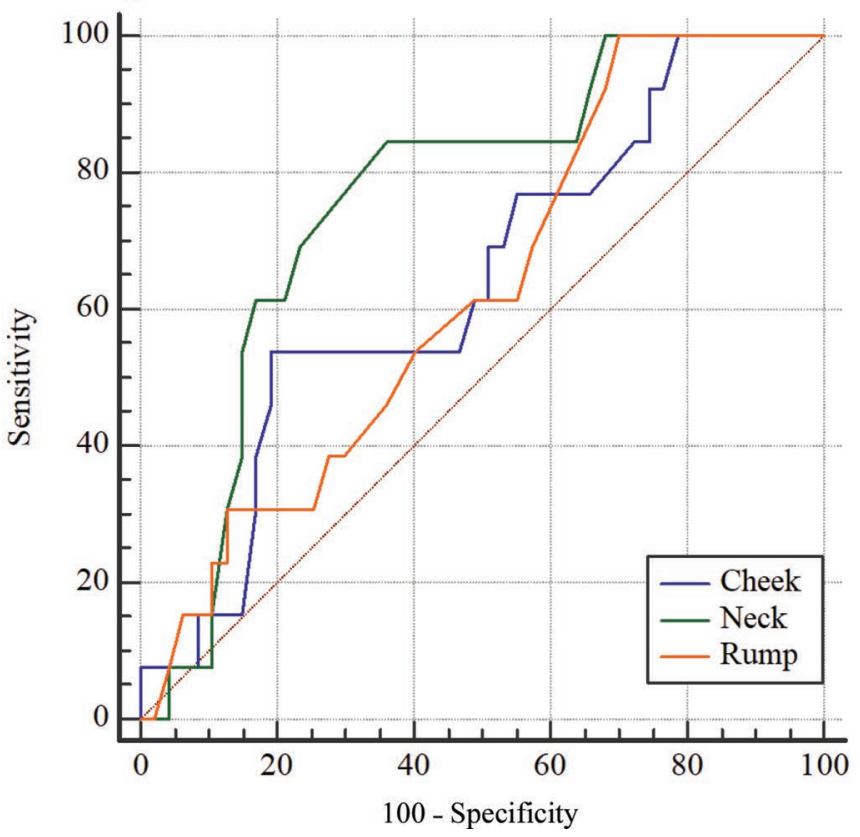

B

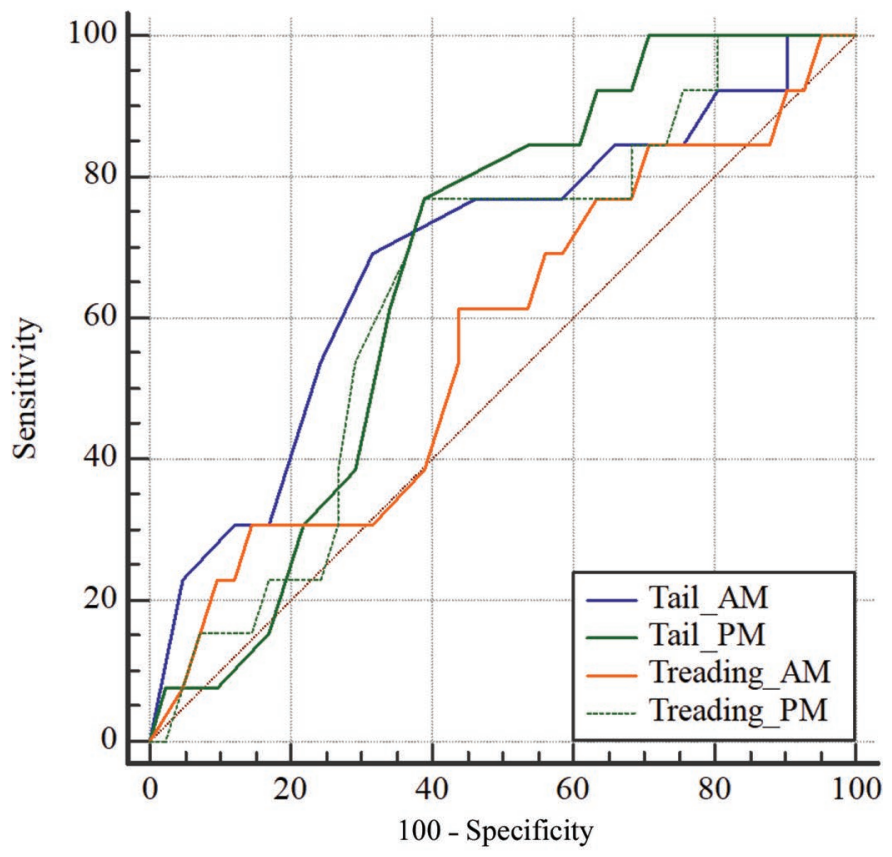

$\mathrm{D}$

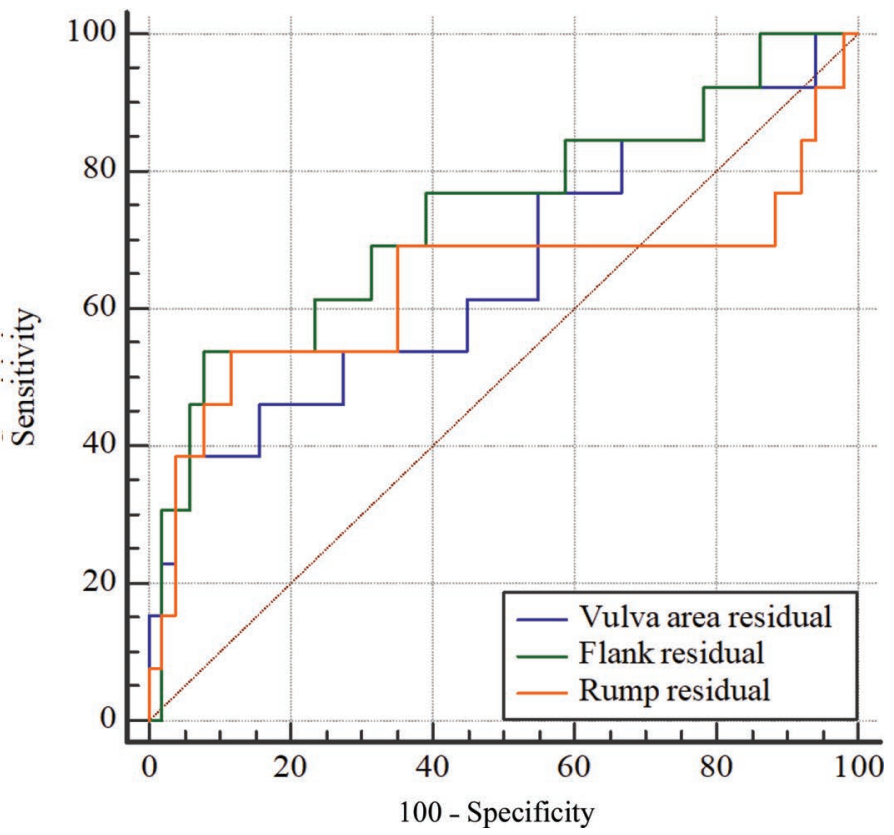

Figure 3. (A) Receiver operating characteristic curves comparison in synchronized (Synch) cows of progesterone $(P=0.01)$ concentrations and follicular size on $\mathrm{d}-2(P=0.01)$ during the estrous period preceding ovulation. (B) Tail movements $(P=0.04)$ and treading frequencies before milking $(P=0.08)$ comparison during estrous period $\mathrm{d}-1$. $(\mathrm{C})$ Raw thermal measurements from the cheek during $\mathrm{d}-1(P=0.07)$, neck during $\mathrm{d}-2(P=0.01)$, and rump during $\mathrm{d}-2(P=0.19)$. (D) Residual thermal measurements from the vulva area $(P=0.1)$, flank $(P$ $=0.01)$, and rump at $\mathrm{d}-2(P=0.24)$.

-5 to -3 ) and ovulation period (d 0) by setting a specific referent test value dependent on the variable.

All behavioral parameters were compared by treatment wherein treading frequency was the only behavior variable found to be greater in pregnant cows. Increased treading of the back legs in pregnant cows could be the result of either increased fluid retention or discomfort in the legs as gestation progressed. It is also impos- 
sible to rule out that treading behavior increases in anticipation of milking in both control and Synch cows because a decrease in treading is observed postmilking. However, the decrease in treading frequency observed during estrus within Synch cows could be due to an overall decrease in activity observed during the onset of estrus (e.g., standing to be mounted; Sveberg et al., 2011), which control cows did not experience. As such, treading behavior may have multiple causal factors, including discomfort, anticipation of milking, or the onset of estrus. In contrast, tail movement frequency did not vary relative to milking time and exhibited a distinct frequency as ovulation approached in Synch cows. In particular, tail movement frequency exhibited a characteristic pattern before ovulation in cyclic cows. Specifically, 48 h before ovulation, Synch cows exhibited increased tail activity followed by a decrease in tail activity $24 \mathrm{~h}$ before ovulation. One possible explanation for this is that estrus behavior is characterized by increased activity followed by the onset of standing estrus (i.e., the receptive period). Estrus has been described in 2 stages: an increase in activity (e.g., walking, mounting, and restlessness) and the appearance of secondary signs (e.g., vaginal mucus discharge) during the first $6 \mathrm{~h}$ of the estrous period, and, second, the onset of lordosis (or standing to be mounted), which is characterized by a decrease in activity in the last $3 \mathrm{~h}$ of estrus (Sveberg et al., 2011). In this regard, our findings appear to be similar to those described by Sveberg et al. (2011), and the increase in tail movement on $\mathrm{d}-2$ could be explained as part of the restlessness associated with the onset of estrus. Another possible explanation for the increase in tail movements on $d-2$ is that vulva swelling $48 \mathrm{~h}$ before ovulation may have led to temporary discomfort, thereby resulting in increased tail movements, which then subsided. Sumiyoshi et al. (2014) reported swelling of the vulva and contraction of the uterus and uterine horns during the peak of estradiol 24 to $30 \mathrm{~h}$ before ovulation followed by an intravaginal relaxation 6 to $18 \mathrm{~h}$ before ovulation, which fits with the timing of the peak in tail movements observed in the current study. Additionally, Fricke et al. (2014) reported an increase in activity using an activity monitoring system (Heatime, SCR Engineers Ltd., Netanya, Israel) after a second $\mathrm{PGF}_{2 \alpha}$ injection and a follicle $>10 \mathrm{~mm}$ in diameter in a Presynch-Ovsynch protocol, which also coincides with our results. However, we cannot rule out the possibility that the increase in tail movement frequency $48 \mathrm{~h}$ before ovulation is the result of a type I statistical error because tail movement frequency at $\mathrm{d}-2$ is higher than most other days, not just around the day of ovulation. In contrast, $\mathrm{P}_{4}$ concentrations in the days leading up to ovulation are highly organized. Thus, we cannot state that the peak in tail movement frequency
$48 \mathrm{~h}$ before ovulation is itself predictive of ovulation. However, the decrease in tail movement frequency on $\mathrm{d}-1$ may be the better estrus indicator, as tail movements become more still as estrus approaches. Similar to the findings of Guesgen and Bench (2018), it may not be an increase in behavior frequency but rather the subsequent decrease in frequency that is the better estrus alert. Anecdotally, members of the research team noted that when tail movement frequency decreased the day before confirmed ovulation, cyclic cows tended to be more still overall and to move their tail to one side, and hold it there, to expose the vulva.

It should be noted that the present study did not differentiate between various types of tail events (e.g., left-right movements) or identify the magnitude of movements (e.g., distance and velocity) during the estrous period. Additional factors that can affect tail movements include staff presence, proximity of the milking machine, or intercow variation attributed to age, previous experiences, seasonal effects (e.g., presence of flies), or physical attributes (e.g., tail docking or broken tail) that can make it difficult to detect more subtle changes in tail movements if used as the sole indicator of estrus. Further, the interobserver reliability of $85 \%$ (Kappa coefficient) was just below of the acceptable value for behavior observations (90\%). The current study found tail movement frequency very challenging to score for the rapid movements and large amount of events. For that reason, the statistic analysis may underestimate the influence of tail movement frequency in the experiment. We are not aware of any of the above influencing our findings; however, it is possible that the observed increase in tail movement frequency on $\mathrm{d}-4$ could have been a result of the injection of $\mathrm{PGF}_{2 \alpha}$. Burne et al. (2002) found that $\mathrm{PGF}_{2 \alpha}$ increases libido and behaviors following treatment; thus, it is not unexpected to see an increase in movement within the cyclic cows in the current study on $\mathrm{d}-5$ and -4 when the prostaglandin was injected $12 \mathrm{~h}$ apart.

The second objective of this research was to evaluate the accuracy of IRT and behavioral biometric parameters as noninvasive estrus indicators in cyclic dairy cows in a tiestall housing system. Our results found changes in both thermal and behavioral parameters 48 and $24 \mathrm{~h}$ before confirmed ovulation, during the same time period when $\mathrm{P}_{4}$ concentrations are decreasing and the appearance of the dominant follicle occurs. However, radiated heat and behavior frequencies were both found to increase and decrease in the days leading up to ovulation, suggesting a characteristic sequence of thermal and behavior events, not merely a single event or value to serve as an indicator of estrus.

To evaluate all thermal and behavioral biometric variables for estrus detection purposes, J index was used 
to represent the relative contribution of true estrus and non-estrus test results by expressing proportions within their respective groups (estrus and non-estrus). Decisions regarding behavioral and radiated temperature variable referent values can be adjusted depending on the specific breeding management strategy and factors being monitored. Given that the number of non-estrus days are limited to a few days within the current study, this could have been reflected in lower specificity results. However, because the current study's focus is on test performance and the ability to find true positives, an emphasis has been placed on sensitivity results. As such, the inclusion of additional non-estrus days would be expected to have had little effect on positive predictive values. In the case of estrus diagnosis, higher true positives are weighted heavier compared with true negatives because AI is not as expensive as missing when to inseminate and the integrity of the cows is not in jeopardy.

The optimal referent test values for this study were identified according to $\mathrm{J}$ index $(>0.30)$ and $\mathrm{AUC}$ values $(>0.60)$ for both behavior and IRT data to ensure an estrus detection rate of $55 \%$ (similar to visual observation) for comparison purposes. For radiated temperature, the test of performance using ROC curves varied by anatomical location, sample day, and the estrus detection period ( 48 vs. 24 h). Five anatomical locations were identified as diagnostically significant using raw thermal data as a 24-h estrus alert and 4 anatomical locations as a 48-h estrus alert. Adjustments to eliminate ambient environmental effects on radiated temperature were accomplished via the calculation of residual temperatures. In effect, the residual temperature can be regarded as that fraction of radiated temperature that is not accounted for by thermoregulation to the environment (Cook et al., 2016). In the present study, the residual temperature is the fraction of radiated temperature most likely associated with hormone-induced temperature changes during estrus. The residual temperature variable increased the number of estrus alerts per anatomical locations with $\mathrm{J}$ index $>0.30$ and AUC $>0.60$ (Figure 4).

Shifting behavior, neighbor interaction, lying, and drinking events did not present $\mathrm{J}$ index values $>0.30$, which suggests that they are not practical for estrus detection application. Explanations of poor tests of performance for shifting, neighbor interactions, lying, and drinking events may be attributed to the frequency of data collection and proximity to milking events. Around milking ( $5 \mathrm{~min}$ before, $5 \mathrm{~min}$ during, and $5 \mathrm{~min}$ after), most cows tended to increase stepping (treading) and tail movements, whereas shifting, neighbor interaction, drinking, and lying behaviors may be more accurately described as sporadic events. In contrast,

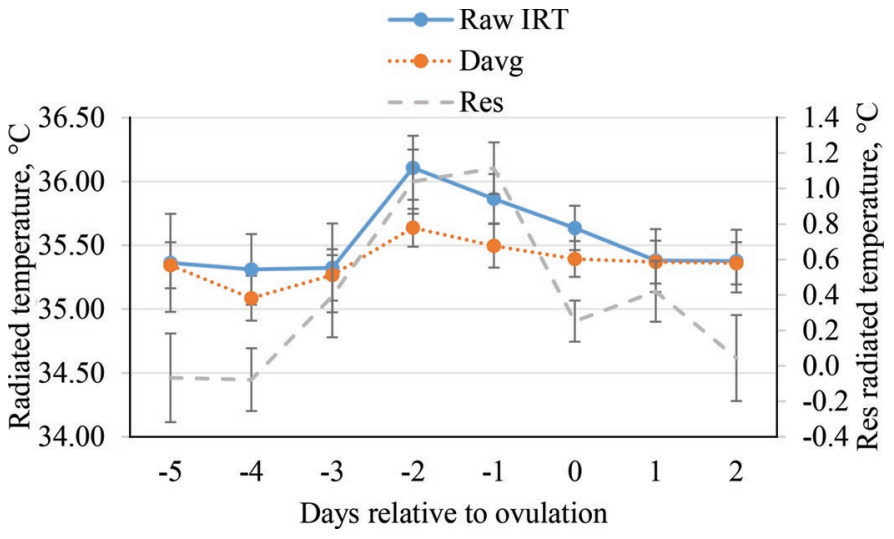

Figure 4. Radiated temperature increase of different thermal data measurements on days approaching ovulation (d 0) in synchronized (Synch) cows for the vulva area during the afternoon milking. Days -2 and -1 coincided with estrus (following decreases in progesterone concentrations and follicular diameter). Raw infrared thermography (IRT; $P=0.01)$ and SEM temperature are compared with the daily average $(P=0.18)$ of radiated temperature (Davg) and SEM as well as the residual temperature $(P=0.01)$. Res (residual IRT temperature) is calculated by subtracting the estimated IRT temperature based on ambient temperature and observed IRT temperature from the actual radiated temperature of each anatomical location.

based on ROC analysis, 3 of 12 tail movement frequency and 1 of 12 treading movement frequency sample times met the $\mathrm{J}$ index $>0.30$ and AUC $>0.60$ criteria. As such, tail and treading movements comply with the requirements of biometrical parameters that can detect estrus within a window of $24 \mathrm{~h}$. In particular, tail movement frequency was found to be more effective more often; however, capturing tail movements in a herd of cows is time consuming and impractical in barn unless these parameters can be captured and analyzed using an automated system. As such, our findings suggest that it is worth further research into the combined use of infrared thermal data and subtle tail movements in naturally cycling cows and over the full estrous cycle as an indicator of estrus as part of an automated infrared technology platform.

\section{CONCLUSIONS}

The first objective of this research was to characterize behavioral and thermal biometric patterns of pregnant and cyclic cows around milking time in a tiestall housing system. We hypothesized that subtle changes in behavior biometrics associated with lordosis (i.e., standing estrus) and fluctuations in radiated heat emitted from specific anatomical locations are able to differentiate the physiological status (pregnant vs. cyclic and cyclic non-estrus vs. cyclic estrus) in dairy cows. The results of the current study found both thermal and behavioral differences between pregnant and cyclic cows. 
Radiated temperatures from the vulva area, muzzle, cheek, eye, neck, and withers and treading frequency during milking increased in cyclic cows in the days approaching ovulation compared with pregnant cows. The second objective of this research was to evaluate the accuracy of IRT and behavioral biometric parameters as noninvasive estrus indicators in cyclic dairy cows in a tiestall housing system. Our second hypothesis was that behavior biometrics and fluctuations in radiated heat are able to produce estrus alerts with an estrus detection rate greater than visual estrus detection rates (e.g., $>55 \%$ ) using a $\mathrm{J}$ index $>0.30$ and $\mathrm{AUC}>0.60$. Multiple behavior (e.g., tail and treading movements) and thermal (e.g., residual) biometrics were found to meet the predetermined criteria as estrus alerts. Specifically, fluctuations in radiated temperature from the vulva, muzzle, eye, neck, cheek, and withers in addition to tail movements before ovulation were associated with estrus indicators in tiestall-housed cows.

\section{ACKNOWLEDGMENTS}

The authors thank the Alberta Livestock and Meat Agency (ALMA, Edmonton, AB, Canada) and Alberta Milk (Edmonton, AB, Canada) for providing funding for this research. In addition, the authors acknowledge the Department of Agricultural, Food and Nutritional Science (Edmonton, AB, Canada) at the University of Alberta, Animal Inframetrics (Lacombe, AB, Canada), and InterAg New Zealand (Hamilton, New Zealand) for providing in-kind support as well as the Livestock Research Branch (Edmonton, AB, Canada) of Alberta Agriculture and Forestry for providing ultrasound equipment. We further acknowledge Emmanuel Opoku Yeboah (University of Alberta) for assistance with IRT, Gobikrushanth Mohanathas (University of Alberta) for assistance with ultrasound scanning, the many undergraduate students (A. Pitagan, E. Carlson, N. Zukiwsky, A. Himmelreich, M. Lin, M. Lucki, and A. L'Hirondelle; all at University of Alberta) who assisted with behavior observations, and the University of Alberta Dairy Research and Technology Centre (Edmonton, AB, Canada) staff who provided assistance with day-to-day animal care and handling.

\section{REFERENCES}

At-Taras, E. E., and S. L. Spahr. 2001. Detection and characterization of estrus in dairy cattle with an electronic heatmount detector and an electronic activity tag. J. Dairy Sci. 84:792-798. https://doi .org/10.3168/jds.S0022-0302(01)74535-3.

Aungier, S. P. M., J. F. Roche, M. Sheehy, and M. A. Crowe. 2012. Effects of management and health on the use of activity monitoring for estrus detection in dairy cows. J. Dairy Sci. 95:2452-2466. https://doi.org/10.3168/jds.2011-4653.
Burne, T. H. J., P. J. E. Murfitt, and C. L. Gilbert. 2002. C-fos mRNA expression associated with $\mathrm{PGF}_{2 \mathrm{n}}$-induced nest-building behaviour in female pigs. Brain Res. Mol. Brain Res. 104:31-37. https://doi .org/10.1016/S0169-328X(02)00199-7.

Canadian Council on Animal Care. 2009. Guidelines on the Care and Use of Farm Animals in Research, Teaching and Testing. CCAC, Ottawa, ON, Canada.

Chiang, M. F., P. Lin, L. Lin, H. Chiou, C. Chien, S. Chu, and W. Chiu. 2008. Mass screening of suspected febrile patients with remote-sensing infrared thermography: Alarm temperature and optimal distance. J. Formos. Med. Assoc. 107:937-944. https://doi .org/10.1016/S0929-6646(09)60017-6.

Cook, N., E. Timsit, J. Colyn, B. Chabot, T. Liu, B. Wolfger, and A. Schaefer. 2016. Assessing consistency in radiated thermal output of beef steers by infrared thermography. J. Imaging 2:1-17. https: //doi.org/10.3390/jimaging2030021.

de Vries, A., and B. J. Conlin. 2003. Economic value of timely determination of unexpected decreases in detection of estrus using control charts. J. Dairy Sci. 86:3516-3526. https://doi.org/10.3168/jds .S0022-0302(03)73956-3.

Denis-Robichaud, J., R. L. Cerri, A. Jones-Bitton, and S. J. LeBlanc. 2016. Survey of reproduction management on Canadian dairy farms. J. Dairy Sci. 99:9339-9351. https://doi.org/10.3168/ jds.2016-11445.

Felton, C. A., M. G. Colazo, P. Ponce-Barajas, C. J. Bench, and D. J. Ambrose. 2012. Dairy cows continuously-housed in tie-stalls failed to manifest activity changes during estrus. Can. J. Anim. Sci. 92:189-196. https://doi.org/10.4141/cjas2011-134.

Firk, R., E. Stamer, W. Junge, and J. Krieter. 2003. Improving oestrus detection by combination of activity measurements with information about previous oestrus cases. Livest. Prod. Sci. 82:97-103. https://doi.org/10.1016/S0301-6226(02)00306-8.

Frascarolo, P., Y. Shutz, and E. Jequier. 1990. Decreased thermal conductance during the luteal phase of the menstrual cycle in women. J. Appl. Physiol. 69:2029-2033. https://doi.org/10.1152/jappl .1990.69.6.2029.

Fricke, P. M., P. D. Carvalho, J. O. Giordano, A. Valenza, G. Lopes Jr., and M. C. Amundson. 2014. Expression and detection of estrus in dairy cows: The role of new technologies. Animal 8(Suppl. 1):134-143. https://doi.org/10.1017/S1751731114000299.

Guesgen, M. J., and C. J. Bench. 2018. Using kinematics to detect micro-behavioural changes relative to ovulation in naturally cycling tie-stall dairy heifers. Livest. Sci. 207:126-132. https://doi .org/10.1016/j.livsci.2017.11.019.

Hittinger, M. A., J. D. Ambrose, and J. P. Kastelic. 2004. Luteolysis, onset of estrus, and ovulation in Holstein heifers given prostaglandin F2alpha concurrent with, or 24 hours prior to, removal of an intravaginal, progesterone-releasing device. Can. J. Vet. Res. 68:283-287.

Hoffmann, G., M. Schmidt, C. Ammon, S. Rose-Meierhofer, O. Burfeind, W. Heuwieser, and W. Berg. 2013. Monitoring the body temperature of cows and calves using video recordings from an infrared thermography camera. Vet. Res. Commun. 37:91-99. https: //doi.org/10.1007/s11259-012-9549-3

Holman, A., J. Thompson, J. E. Routly, J. Cameron, D. N. Jones, D. Grove-White, R. F. Smith, and H. Dodson. 2011. Comparison of oestrus detection methods in dairy cattle. Vet. Rec. 169:47-52. https://doi.org/10.1136/vr.d2344.

Hurnik, J. F., A. B. Webster, and S. DeBoer. 1985. An investigation of skin temperature differentials in relation to estrus in dairy cattle using a thermal infrared scanning technique. J. Anim. Sci. 61:1095-1102.

Kyle, B. L., A. D. Kennedy, and J. A. Small. 1998. Measurement of vaginal temperature by radiotelemetry for the prediction of estrus in beef cows. Theriogenology 49:1437-1449.

Lewis, G. S., and S. K. Newman. 1984. Changes throughout estrous cycles of variables that might indicate estrus in dairy cows. J. Dairy Sci. 67:146-152. https://doi.org/10.3168/jds.S0022-0302(84)81278 -3 .

Martinez, M. F., J. P. Kastelic, M. G. Colazo, and R. J. Mapletoft. 2007. Effects of estradiol on gonadotrophin release, estrus and ovu- 
lation in CIDR-treated beef cattle. Domest. Anim. Endocrinol. 33:77-90. https://doi.org/10.1016/j.domaniend.2006.04.009.

Metz-Stefanowska, J., P. J. M. Huijsmans, P. H. Hogewerf, A. H. Ipema, and E. Keen. 1992. Behaviour of cows before, during and after milking with an automatic milking system. EAAP Publ. 65:278288. https://doi.org/10.1016/S0168-1591(98)00229-9.

Michaelis, I., O. Burfeind, and W. Heuwieser. 2014. Evaluation of oestrous detection in dairy cattle comparing an automated activity monitoring system to visual observation. Reprod. Domest. Anim. 49:621-628. https://doi.org/10.1111/rda.12337.

Montanholi, Y. R., N. E. Odongo, K. C. Swanson, F. S. Schenkel, B. W. McBride, and S. P. Miller. 2008. Application of infrared thermography as an indicator of heat and methane production and its use in the study of skin temperature in response to physiological events in dairy cattle (Bos taurus). J. Therm. Biol. 33:468-475. https://doi.org/10.1016/j.jtherbio.2008.09.001.

National Research Council. 2001. Nutrient Requirements of Dairy Cattle. 7th rev. ed. Natl. Acad. Press, Washington, DC.

Obuchowski, N. A. 2005. Fundamentals of clinical research for radiologists: ROC analysis. AJR Am. J. Roentgenol. 184:364-372. https: //doi.org/10.2214/ajr.184.2.01840364.

Palmer, M. A., G. Olmos, L. A. Boyle, and J. F. Mee. 2010. Estrus detection and estrus characteristics in housed and pastured Holstein-Friesian cows. Theriogenology 74:255-264. https://doi.org/ 10.1016/j.theriogenology.2010.02.009.

Perrya, G. A., O. L. Swansona, E. L. Larimorea, B. L. Perrya, G. D. Djirab, and R. A. Cushmanc. 2017. Relationship of follicle size and concentrations of estradiol among cows exhibiting or not exhibiting estrus during a fixed-time AI protocol. Theriogenology 81:925-935. https://doi.org/10.1016/j.domaniend.2014.02.001.

Rae, D. O., P. J. Chenoweth, M. A. Giangreco, P. W. Dixon, and F. L. Bennett. 1999. Assessment of estrus detection by visual observation and electronic detection methods and characterization of factors associated with estrus and pregnancy in beef heifers. Theriogenology 51:1121-1132. https://doi.org/10.1016/S0093 $-691 X(99) 80015-6$.

Redden, K. D., A. D. Kennedy, J. R. Ingalls, and T. L. Gilson. 1993. Detection of estrus by radiotelemetric monitoring of vaginal and ear skin temperature and pedometer measurements of activity. J. Dairy Sci. 76:713-721. https://doi.org/10.3168/jds.S0022 -0302(93)77394-4.

Roelofs, J. B., F. J. C. M. Van Eerdenburg, N. M. Soede, and B. Kemp. 2005. Pedometer readings for estrous detection and as predictor for time of ovulation in dairy cattle. Theriogenology 64:1690-1703. https://doi.org/10.1016/j.theriogenology.2005.04.004.

Rosner, B. 2006. Fundamentals of Biostatistics. 6th ed. ThompsonBrooks/Cole, Belmont, CA.

Sanderink, F. E. P., J. W. Gerritsen, P. W. G. Groot Koerkamp, and S. V. Mourik. 2017. Automatic detection of oestrus cows via breath sampling with an electronic nose: A pilot study. Biosyst. Eng. 156:1-6. https://doi.org/10.1016/j.biosystemseng.2017.01 .004 .

Sangsritavong, S., D. K. Combs, R. Sartori, and M. C. Wiltbank. 2002. High feed intake increases blood flow and metabolism of progesterone and estradiol-17 $\beta$ in dairy cattle. J. Dairy Sci. 85:2831-2842. https://doi.org/10.3168/jds.S0022-0302(02)74370-1.

Schaefer, A. L., N. J. Cook, C. Bench, J. B. Chabot, J. Colyn, T. Liu, E. K. Okine, M. Stewart, and J. R. Webster. 2012. The noninvasive and automated detection of bovine respiratory disease onset in receiver calves using infrared thermography. Res. Vet. Sci. 93:928-935. https://doi.org/10.1016/j.rvsc.2011.09.021.

Senger, P. L. 1994. The estrus detection problem: New concepts, technologies, and possibilities. J. Dairy Sci. 77:2745-2753. https://doi .org/10.3168/jds.S0022-0302(94)77217-9.

Sumiyoshi, T., T. Tanaka, and H. Kamomae. 2014. Relationships between the appearances and changes of estrous signs and the estradiol-17 $\beta$ peak, luteinizing hormone surge and ovulation during the periovulatory period in lactating dairy cows kept in tiestalls. J. Reprod. Dev. 60:106-114. https://doi.org/10.1262/jrd .2013-119.

Suthar, V. S., O. Burfeind, J. S. Patel, A. J. Dhami, and W. Heuwieser. 2011. Body temperature around induced estrus in dairy cows. J. Dairy Sci. 94:2368-2373. https://doi.org/10.3168/jds.2010 -3858 .

Sveberg, G., A. O. Refsdal, H. W. Erhard, E. Kommisrud, M. Aldrin, I. F. Tvete, F. Buckley, A. Waldmann, and E. Ropstad. 2011. Behavior of lactating Holstein-Friesian cows during spontaneous cycles of estrus. J. Dairy Sci. 94:1289-1301. https://doi.org/10 .3168/jds.2010-3570.

Talukder, S., K. L. Kerrisk, L. Ingenhoff, P. C. Thomson, S. C. Garcia and P. Celi. 2014. Infrared technology for estrus detection and as a predictor of time of ovulation in dairy cows in a pasture-based system. Theriogenology 81:925-935. https://doi.org/10.1016/j .theriogenology.2014.01.009.

Walton, J. S., and G. J. King. 1986. Indicators of estrus in Holstein cows housed in tie stalls. J. Dairy Sci. 69:2966-2973. https://doi .org/10.3168/jds.S0022-0302(86)80754-8.

Xu, Z. Z., D. J. McKnight, R. Vishwanath, C. J. Pitt, and L. J. Burton. 1998. Estrus detection using radiotelemetry or visual observation and tailing painting for dairy cows on pasture. J. Dairy Sci. 81:2890-2896. https://doi.org/10.3168/jds.S0022-0302(98)75849 $-7$.

Yániz, J. L., P. Santolaria, A. Giribet, and F. Lopez-Gatius. 2006. Factors affecting walking activity at estrus during postpartum period and subsequent fertility in dairy cows. Theriogenology 66:19431950. https://doi.org/10.1016/j.theriogenology.2006.05.013. 